\title{
Supercritical CO2 Cycle System Optimization of Marine Diesel Engine Waste Heat Recovery
}

\author{
Shengya Hou ${ }^{1, \text { a }}$, Wenping Zhang ${ }^{1, \mathrm{~b}}$, Ziwei Zeng ${ }^{1, \mathrm{c}}$ andJiachen $\mathrm{Ji}^{1, \mathrm{~d}}$ \\ ${ }^{1}$ Harbin Engineering University,Harbin,China \\ ahoushengya@hrbeu.edu.cn, bzhangwenping@hrbeu.edu.cn, 'zengziwei@ hrbeu.edu.cn, \\ dijiachen@hrbeu.edu.cn,
}

\begin{abstract}
Keywords: Diesel engine; Waste heat recovery; Supercritical $\mathrm{CO}_{2}$ cycle system; System optimization

Abstract. The exhaust gas of marine diesel engine loses a lot of energy when the exhaust discharged directly. Making good use of diesel engine exhaust gas to generate electricity is helpful to improve the thermal efficiency. Supercritical carbon dioxide cycle is not only with high cycle efficiency, but its devices have advantages of compact structure, can be realized easily as well. The waste gas can be used as the heat source of supercritical carbon dioxide cycle for power generation, which is conducive to save fuel and reduce the costs. So it is necessary to optimize the supercritical $\mathrm{CO}_{2}$ circulation system based on the characteristics of the Marine diesel engine, to achieve the purpose of practical shipment.
\end{abstract}

\section{Background}

As the economy develops rapidly, oil resources are over exploited and used. Marine diesel engine costs lots of oil, so the energy-saving problem of diesel engine raises more and more attention. Reducing fuel consumption and improving power plant economy are particularly important. According to the heat balance of diesel engine, only 30\% of the energy from fuel burning is used for power output, and (50 60) \% of energy is taken away by the exhaust waste heat and cooling water, wasted in vain. If this part of the energy can be reasonably used into the daily operation of ship such as power generation, refrigeration, making fresh water, the fuel consumption can be reduced, improving the power plant economy.

Supercritical $\mathrm{CO}_{2}$ cycle systems are widely applied to solar energy utilization, nuclear energy utilization, geothermal energy utilization, and waste heat utilization. At present, researches in using the solar energy, nuclear power and geothermal energy have been carried out; such as a solar rankine cycle with supercritical $\mathrm{CO}_{2}$ as working medium presented by Xinrong Zhang ${ }^{[1]}$, a Beijing University professor. And his experimental results showed that $\mathrm{CO}_{2}$ can be effectively heated to $165^{\circ} \mathrm{C}$ in solar thermal collectors, and the heat can be effectively recycled, showing that this cycle can achieve higher power generation efficiency and heat recovery efficiency. Fahad A. Al-Sulaiman ${ }^{[2]}$ conducted a thermodynamic comparison of five supercritical carbon dioxide Brayton cycles integrated with a solar power tower, and he found that the regenerative Brayton cycle, although simpler in configuration, shows comparable performance to the recompression Brayton cycle. Sandia national laboratories in the United States ${ }^{[3,4]}$, in view of nuclear power utilization efficiency, took the lead for the research of the supercritical carbon dioxide closed cycle, by doing a lot of experiments to study supercritical carbon dioxide problems in closed cycle including compression, friction bearings, seals, and other problems. And its cycle experiment device got the power generation efficiency at nearly 50\%. On March 4st, 2011, the Sandia Labs on its website officially announced that they had mastered the key technology of supercritical carbon dioxide in closed cycle. But there is no researches on Marine diesel engine waste heat utilization. It is of great significance for marine diesel energy saving to carry out the research of supercritical $\mathrm{CO}_{2}$ cycle system according to the operation characteristics of marine diesel engine. 


\section{Supercritical CO2 fluid properties}

Supercritical Fluid (SCF) is at above the critical temperature (Tc) and critical pressure (Pc), a fluid at between vapor and liquid. Supercritical is a special status of the substance, and the substance at this state is at a state neither vapor nor liquid, with many special properties.

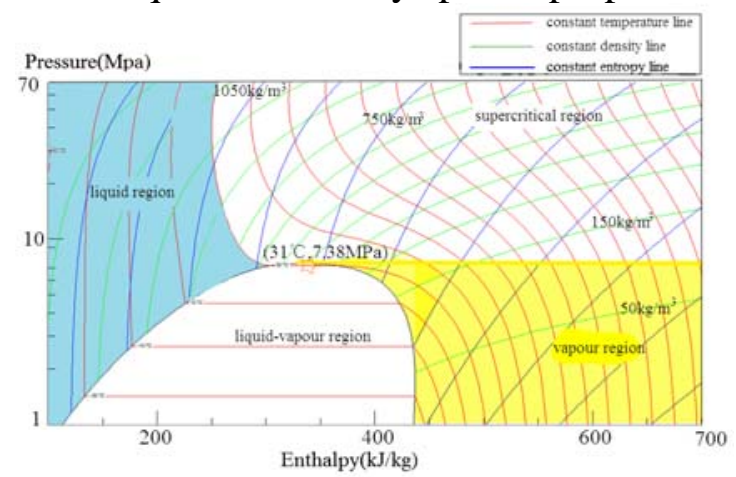

Fig.1. $\mathrm{CO}_{2}$ pressure enthalpy

As shown in Fig.1, in the area surrounded by abscissa and ordinate, the area surrounded by $31^{\circ} \mathrm{C}$-isotherm and borderline is the liquid zone with the density as $65 \%-80 \%$ of water density; the area surrounded by 7.3 MPa-isobar and borderline is the steam zone with the density as $15 \%$ - $30 \%$ of water density. The area surrounded by critical line is two-phase zone; in addition to the liquid phase and vapor phase, two-phase zone also shows a special region - supercritical region SCF. SCF is a high density fluid of non cohesion. Under the supercritical condition, the difference between liquid and gas completely disappear, and it is a state different from both the vapor state and the liquid state. Critical pressure and critical temperature of supercritical fluids varies due to different molecular structure of substances. The stronger molecular polarity is, the larger molecule is, and the higher critical temperature is, the lower critical pressure is.

Under supercritical conditions, in the process of flow and heat transfer, the physical properties of $\mathrm{CO} 2$ change along with the change of its temperature and pressure, especially in the area near the critical point, a micro change of temperature or pressure will cause great changes in physical properties, causing much effect on the heat physical properties. Therefore, the study of the heat transfer characteristics and regularity of supercritical CO2 has vital significance, and it is also a hotspot of CO2 supercritical circulating system .at present

\section{Establish Supercritical $\mathrm{CO}_{2}$ Circulation System Model}

We used the thermal physical property parameters of CO2 calculated by NIST Refprop ${ }^{[5]}$ software, and then used it to be programmed to do calculation. At the same time, we established models in ASPEN PLUS, so that the supercritical CO2 circulation system simulation and the results of the programming verification can be done, improving the accuracy of the results.

\section{Circulatory System Computational Modeling}

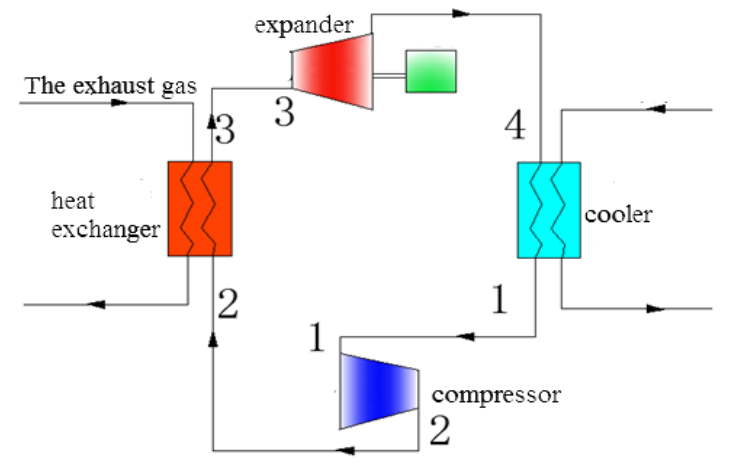

Fig.2. Basic circulatory system

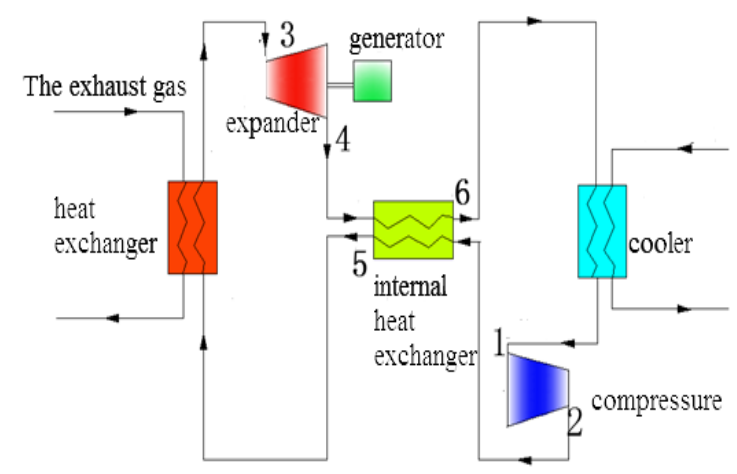

Fig.3. regenerative cycle system 
As shown in Fig.2, the system consists of a compressor, a heat exchanger, an expander and generator set, and a cooler. $\mathrm{CO}_{2}$ is compressed to the supercritical state through the compressor, and absorbs heat in the heat exchanger, and then does work in the expander to generate power. After completing heat transfer in the cooler, $\mathrm{CO}_{2}$ enters the compressor to the next cycle.

The system with IHX consists of the compressor, heat exchanger, expander and generator sets, condenser, and the regenerator as shown in the Fig2. The difference between the simple and the system with IHX is that the system with IHX can recover the energy from the expander outlet.

\section{Results and Discussion}

\section{Regenerative Cycle Compared with Basic Cycle Performance}

According to the rated conditions, we compared the performance of the regenerative cycle to that of the basic cycle. The conditions were set: Heat source temperature as $290^{\circ} \mathrm{C}$, the initial temperature as $31{ }^{\circ} \mathrm{C}$, initial pressure as $7.4 \mathrm{MPa}$, and the maximum pressure changes from 7.7MPa to $20 \mathrm{MPa}$. As shown in Fig.3, the thermal efficiency, exergy efficiency, recycling net power, mass flow rate of regenerative cycle are all higher than those of basic cycle. Therefore, regenerative cycle system is more suitable for recycling diesel engine exhaust.

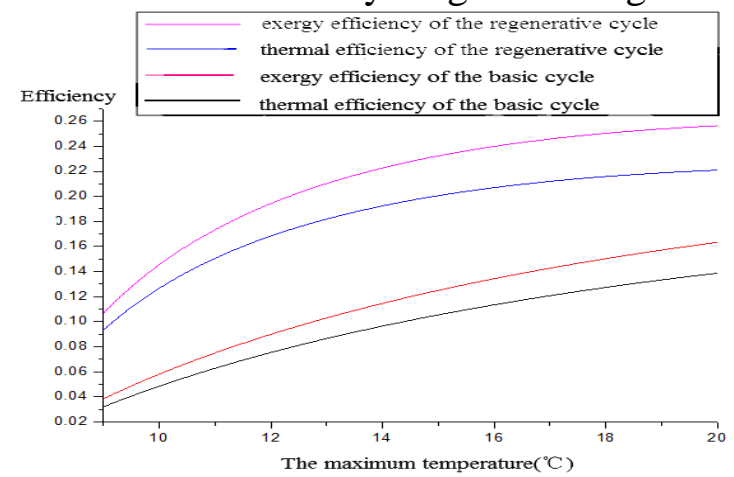

(1)

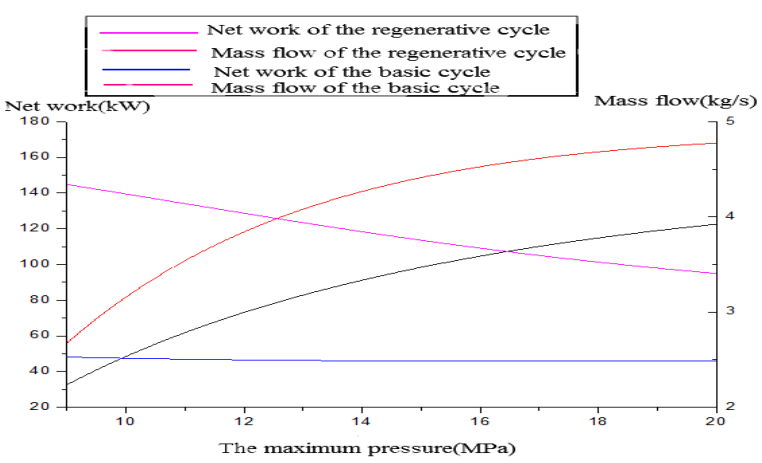

(2)

Fig.3. basic cycle comparison with regenerative cycle

\section{Circulatory System Performance with the Heat Source Temperature Change}

According to rated conditions, we studied the characteristics of regenerative cycle system along with the change of heat source temperature. We set initial temperature as $31^{\circ} \mathrm{C}$, initial pressure as $7.4 \mathrm{MPa}$, and the maximum pressure as $15 \mathrm{Mpa}$, exploring the performance of circulatory system when the heat source temperature change from $150{ }^{\circ} \mathrm{C}$ to $500{ }^{\circ} \mathrm{C}$. The results are shown in Fig. 4 below, with the heat source temperature increasing, the thermal efficiency, exergy efficiency, Cycle net work and fluid mass flow of the circulatory system are all increased. Therefore, the improvement of the heat source temperature is beneficial to the system performance. But when the supercritical CO2 recycling system is used to recycle the waste heat energy of the diesel engine, those are limited by the diesel engine exhaust tem perature.

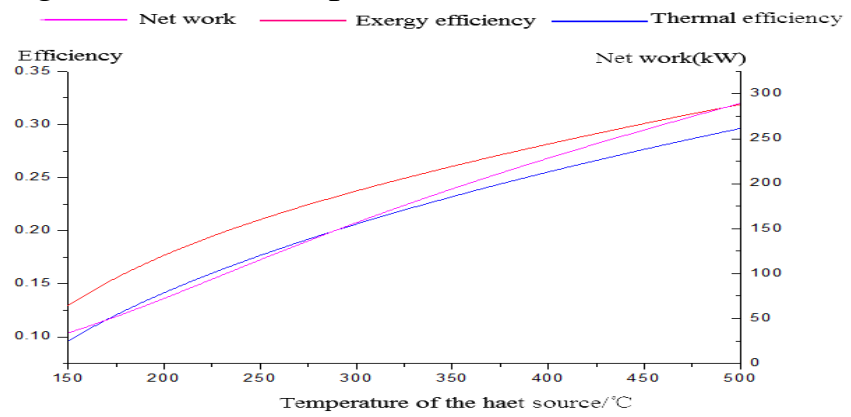

(1)

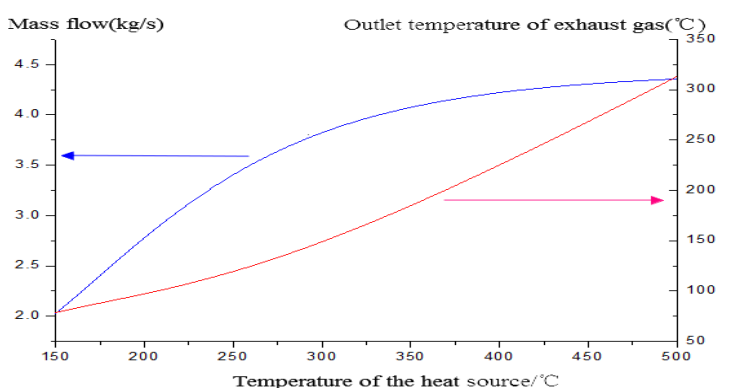

(2)

Fig.4.the performance of the cycle with the heat source temperature change

According to rated conditions, we studied the characteristics of regenerative cycle system along 
with the change of maximum pressure. We set initial temperature as $31^{\circ} \mathrm{C}$, initial pressure as $7.4 \mathrm{MPa}$, and the heat source temperature as $290{ }^{\circ} \mathrm{C}$, exploring changes in the circulatory system performance when the maximum pressure changes from 7.7MPa to 31.4MPa. The results are shown in Fig. 5, that with the increase of the maximum pressure, the thermal efficiency, exergy efficiency, and cycle net work of the circulatory system increased at first rapidly, and these came to increases slowly after 15Mpa.Finally, these parameters slowly decreased after getting a maximum value, the cycle net work gets a maximum value when the pressure reached $27.6 \mathrm{Mpa}$, and the thermal efficiency got a maximum value at $24.1 \mathrm{Mpa}$. Therefore, within the scope of the material, maximize the pressure to the highest point, but at the same time, considering the costs and benefits, we selected the maximum pressure as $15 \mathrm{MPa}$.
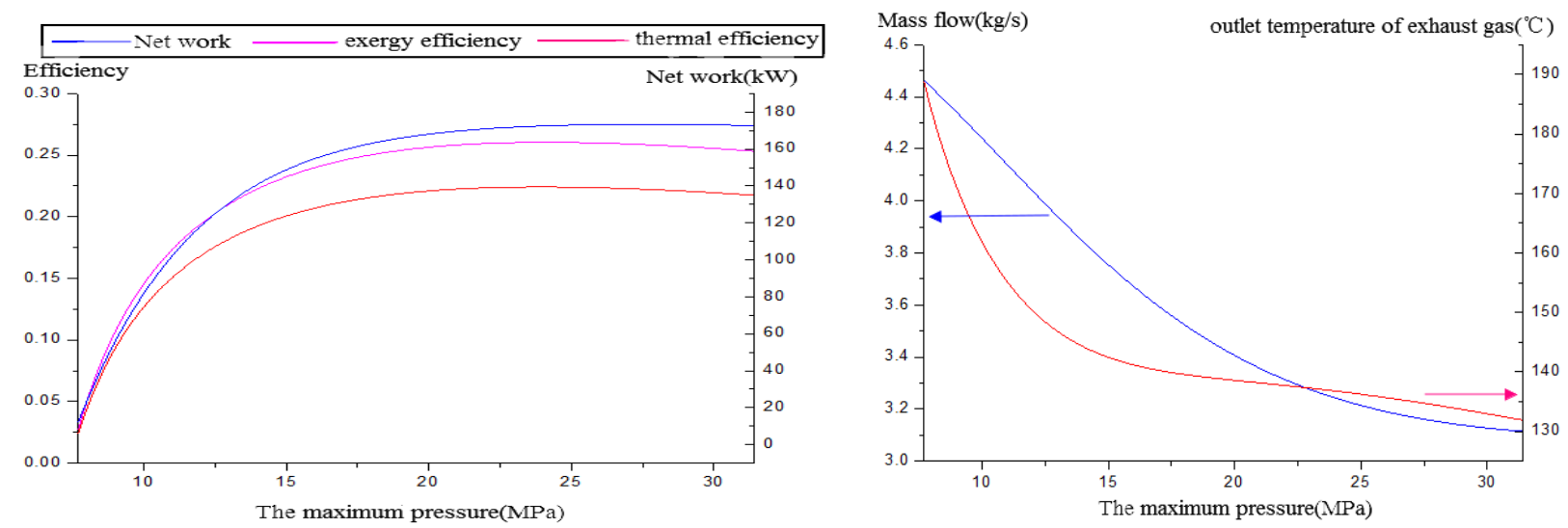

Fig.5. cycle performance with the highest pressure variation

\section{Cycle Performance with the Initial Pressure Change}

According to rated conditions, we studied the characteristics changes of regenerative cycle system along with the change of initial pressure. The conditions were set: initial temperature as $31{ }^{\circ} \mathrm{C}$, the maximum pressure as $15 \mathrm{MPa}$, heat temperature as $290{ }^{\circ} \mathrm{C}$, exploring changes of the circulatory system performance as the initial pressure at 7.3MPa, 7.4MPa, 7.5MPa, 7.6Mpa. Results is shown in Fig. 6 below, compared to other pressures, the net work at 7.3Mpa was significantly lower than that at other pressures. Therefore, that also verified that the supercritical circulating has a better performance compared to the transcritical cycle. By comparing the situations when the pressure respectively at 7.4MPa, 7.5MPa, 7.6MPa, we found that, when the net work of the cycle is set as the objective function, different maximum pressures corresponding to different initial pressure, there exists a max net power. When the maximum pressure is less than $16 \mathrm{MPa}$, the net power corresponding with initial pressure at $7.4 \mathrm{MPa}$ is higher than that of the other two initial pressures. When the maximum pressure is higher than $16 \mathrm{MPa}$, the net power corresponding with initial pressure at $7.5 \mathrm{MPa}$ is higher than that of the other two initial pressures. Therefore, when a circular net work is set as the objective function and the maximum pressure is limited to $16 \mathrm{MPa}$, the selected initial pressure should be as close to the supercritical point as it can be. Pressure either higher or less than the supercritical pressure is not benefit to the cycle characteristics. As the cycle efficiency, when the pressure is less than $16 \mathrm{MPa}$, thermal efficiency corresponding to 7.3 MPa is higher than that of other pressure points. But because the heat source temperature at 7.3MPa is higher than that of other pressure points, the net power is lower than that of the supercritical pressure range. 

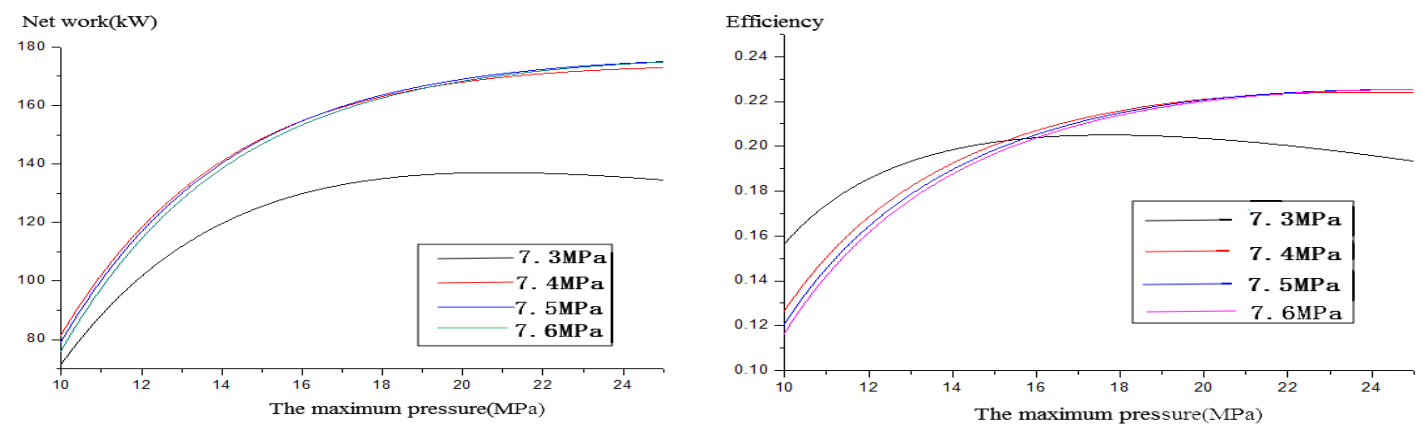

Fig.6. cycle performance with the initial pressure variation

\section{Cycle Performance with the Initial Temperature Change}

According to rated conditions, we studied the characteristics of regenerative cycle system along with the change of initial temperature. Conditions were set: maximum pressure as $15 \mathrm{MPa}$, heat temperature as $290{ }^{\circ} \mathrm{C}$, and then explored changes in the circulatory system performance when the initial temperature was respectively at $31^{\circ} \mathrm{C}, 32^{\circ} \mathrm{C}, 33^{\circ} \mathrm{C}, 34^{\circ} \mathrm{C}, 35^{\circ} \mathrm{C}$. The results are shown below in Fig.7, the lower the initial temperature is, the lower the highest circulation and maximum net power cycle efficiency of the corresponding initial pressure are; and the lower the initial temperature is, the highest circulation and maximum net power cycle efficiency increases compared to other temperature is. By comparing Fig.7 and Fig.8 it can be concluded that the higher the maximum pressure is, the higher its highest circulation and maximum net power cycle efficiency of the corresponding initial pressure are.
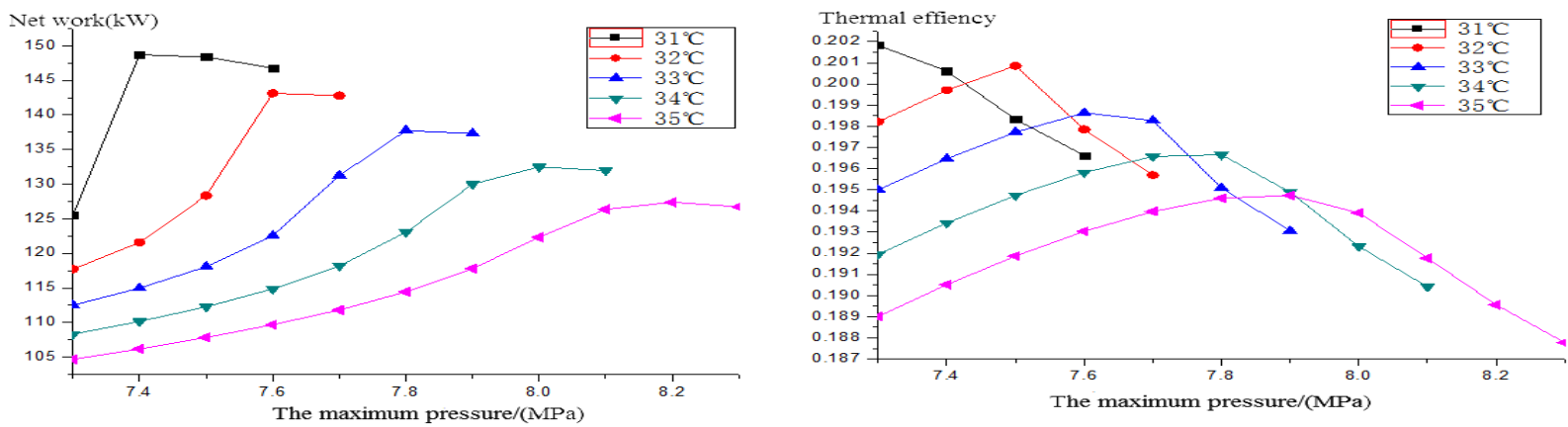

Fig.7. cycle performance with the initial temperature variation (15Mpa)
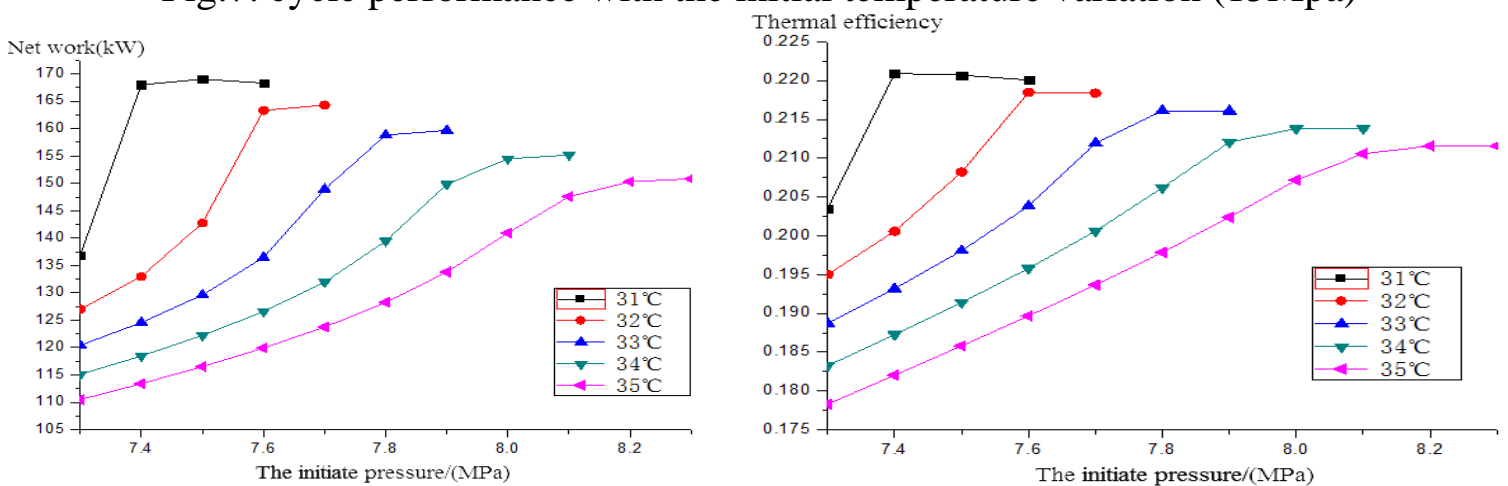

Fig.8. cycle performance with the initial temperature variation (17Mpa)

\section{Cycle Performance with Diesel Engine Working Conditions Change}

Through the above study, we selected an appropriate state parameter point - initial pressure at 7.4MPa, the initial temperature at $31{ }^{\circ} \mathrm{C}$, and the maximum pressure at $15 \mathrm{MPa}$, and then studied circular performance changes with conditions of diesel changing, and the diesel operation point was input using the above heat source designed. Fig.9 shows the changes of regenerative cycle system with the diesel engine condition changing, which can be used as a reference of supercritical $\mathrm{CO}_{2} \mathrm{cycle}$ 
system for diesel engine waste heat recovery.

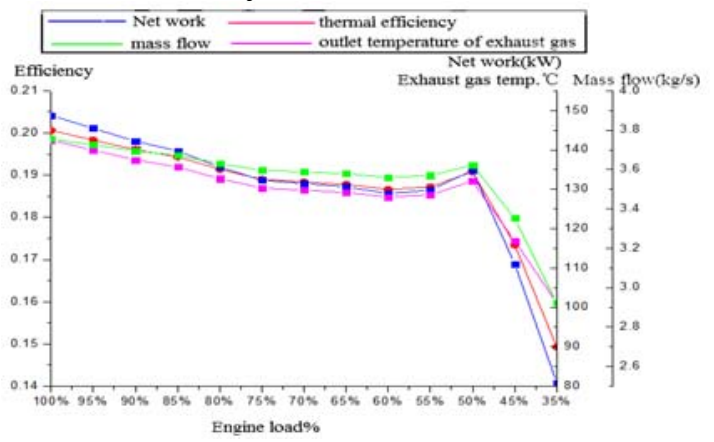

Fig.9. cycle performance with the diesel engine working conditions

\section{Conclusions}

(1) Supercritical CO2 is at a non-gas\&non-liquid state, with many special properties. Under supercritical pressure, the specific heat and thermal conductivity of CO2 are non-linear with temperature, especially in the vicinity of the critical point, the physical properties of CO2 fluid change very intensely, and even a small change at temperature can cause a great change at thermal properties.

(2) The thermal efficiency, exergy efficiency, recycling net power, mass flow rate of regenerative cycle are all higher than those of basic cycle. Therefore, regenerative cycle system is more suitable for recycling diesel engine exhaust. With the heat source temperature increased, the thermal efficiency, exergy efficiency, Cycle net work and fluid flow of the circulatory system are all increased. Therefore, the improvement of the heat source temperature is beneficial to the system performance. With the increase of the maximum pressure, however, the energy efficiency, thermal efficiency of cycle net work of system are increased first but then decreased. Thus, within the scope of the material, we should maximize the pressure to the highest point as we can, and take the costs and benefits into consideration at the same time. The lower the initial temperature is, the greater the highest circulation and maximum net power cycle efficiency are, but the initial temperature is limited to the heat sink temperature.

(3) When setting net work as the objective function, supercritical cycle has better performance compared to the transcritical cycle. For supercritical $\mathrm{CO}_{2}$ cycle system applied to diesel engine waste heat recovery, selecting the appropriate state parameters point - initial pressure at 7.4MPa, the initial temperature at $31{ }^{\circ} \mathrm{C}$ and the maximum pressure at $15 \mathrm{MPa}$ - giving the change of regenerative cycle system with working condition of diesel engine changing, which can be used as a reference for supercritical $\mathrm{CO}_{2}$ recycling system used in diesel engine waste heat recovery.

\section{References}

[1] Xin-Rong Zhang, Hiroshi Yamaguchi, Daisuke Uneno, 2007, Renewable Energy, March 2007, Vol. 32, pp 2617-2628.

[2] Fahad A. Al-Sulaiman, Maimoon Atif . Energy 82 (2015) 61-71.

[3].Edward J P;Steven A W;Milton E V Supercritical $\mathrm{CO}_{2}$ Direct Cycle Gas Fast Reactor (SCGFR) Concept [Sandia report, SAND2011-2525].

[4] Steven A. Wright, Ross F. Radel. Operation and Analysis of a Supercritical $\mathrm{CO}_{2}$ Brayton Cycle [Sandia report, SAND2010-0171].

[5] NIST Standard Reference Database 23, NIST thermodynamic and transport properties of refrigerants and refrigerant mixtures REFPROP, Version 6.01; 1998. 